\title{
Comportamentos de Crianças do Espectro do Autismo com seus Pares no Contexto de Educaçáo Musical ${ }^{1}$ BEHAVIOR OF CHILDREN WITH AUTISM SPECTRUM Disorder WITH PEERS IN THE MUSIC EDUCATIONAL CONTEXT
}

\author{
Paulyane Silva do NASCIMENTO2 \\ Regina Basso ZANON ${ }^{3}$ \\ Cleonice Alves BOSA ${ }^{4}$ \\ João Paulo dos Santos NOBRE 5 \\ Áureo Déo DeFREITAS JÚNIOR ${ }^{6}$ \\ Simone Souza da Costa SILVA ${ }^{7}$
}

\begin{abstract}
RESUMO: o Transtorno do espectro do autismo (TEA) é marcado por prejuízos nas áreas de interação social, comunicação, comportamento e processamento sensorial. Aspectos relacionados a prejuízos no repertório de interaçáo social, bem como estratégias para torná-la mais adequada têm sido amplamente estudados. Dentre estas estratégias, as que utilizam música têm recebido atenção. O presente estudo tem como objetivo investigar os benefícios da educação musical ao desenvolvimento da interação social de crianças com seus pares, focando-se na qualidade e na frequência da apresentaçáo de tais comportamentos. Participaram duas crianças com TEA, com idades de cinco e seis anos, em aulas de percussão em grupo. Os instrumentos utilizados foram a Ficha de dados sociodemográficos e de desenvolvimento, para traçar os perfis dos participantes; e o Protocolo de observação de comportamentos de crianças com TEA com seus pares, para a análise comportamental, durante oito aulas/percussão (240 minutos). Os resultados sugerem que ambos apresentaram tendência ao aumento de iniciativas e respostas espontâneas e à diminuição de comportamentos não funcionais. Verificou-se a ocorrência do uso de estereotipias para tentativas de/e interaçóes, embora esporadicamente. Destacaram-se os papéis do contexto, dos perfis das crianças, e do manejo comportamental por adultos, na promoção de interaçóes.
\end{abstract}

PALAVRAS-CHAVE: Educação Especial.Autismo. Educação Musical. Interação Social.

\begin{abstract}
The Autism Spectrum Disorder (ASD) is characterized by impairments in the areas of social interaction, communication, behavior and sensory processing. Aspects related to difficulties in social interaction repertoire, as well as strategies to help them behave more adequately have been widely studied. Among these strategies, those using music have received attention. The present study aims to investigate the benefits of music education to the social interaction of children with ASD, with their peers, focusing on both the quality and frequency of these behaviors. Two ASD children, aged 5 and 6 years respectively, who attended a percussion class group, participated in the study. The Demographics and Development information enabled the children's profiles to be drawn. The social interaction behaviors were coded using a Behavioral Observation Protocol during 8 sessions (240 minutes). The results suggest that both tended to increase initiatives and spontaneous responses and to decrease non-
\end{abstract}

\footnotetext{
${ }^{1}$ Pesquisa realizada com apoio financeiro da Coordenação de Aperfeiçoamento de Pessoal de Nível Superior (CAPES).

${ }^{2}$ Psicóloga e mestre em Teoria e Pesquisa do Comportamento pela Universidade Federal do Pará. Belém, Pará, Brasil. paulyanenascimento@gmail.com

${ }^{3}$ Psicóloga, especialista em transtornos do desenvolvimento, mestre e doutoranda em Psicologia pela Universidade Federal do Rio Grande do Sul, membro do Núcleo de estudos e pesquisas em transtornos do desenvolvimento. Porto Alegre, Rio Grande do Sul, Brasil.rebzanon@gmail.com

${ }^{4}$ PhD. em Psicologia, Instituto de Psiquiatria, Universidade de Londres. Docente da Universidade Federal do Rio Grande do Sul, Instituto de Psicologia, Departamento de Psicologia do Desenvolvimento e da Personalidade. Porto Alegre, Rio Grande do Sul, Brasil.cleobosa@uol.com.br

${ }^{5}$ Psicólogo e mestre em Teoria e Pesquisa do Comportamento, pela Universidade Federal do Pará. Núcleo de Teoria e Pesquisa do Comportamento (NTPC), Laboratório de Ecologia do Desenvolvimento (LED). Doutorado em andamento em Psicologia (Teoria e Pesquisa do Comportamento) na Universidade Federal do Pará, UFPA, Belém, Pará, Brasil. joaopaulonobre@gmail.com

${ }^{6}$ PhD. em Educação Musical pela Universidade da Carolina do Sul (USA), Departamento de Música. Docente da Universidade Federal do Pará, Instituto de Ciências da Arte, Belém, Pará, Brasil. aureo_freitas@yahoo.com

${ }^{7}$ Doutora em Psicologia, Docente da Universidade Federal do Pará, Programa de Pós-graduação em Teoria e Pesquisa do Comportamento. Belém, Pará, Brasil. symon.ufpa@gmail.com
} 
functional behaviors as the sessions progressed. It was found that stereotypies were used by the ASD children when attempting to interact with others, albeit sporadically. The role of context, of the children's profile and of adult behavioral management of children in promoting interactions was highlighted.

KEYWORDS:Special Education. Autism. Music Education. Social Interaction.

\section{INTRODUÇÁO}

O compartilhamento de experiências de crianças, seja com um adulto ou com parceiros da mesma faixa etária (pares), é um dos fatores que contribuem para o processo de desenvolvimento infantil. Segundo Pedrosa e Carvalho (2009, p.356), é por meio destas relaçóes que a criança atua "[...] construindo e reconstruindo significaçóes sobre objetos e eventos que ocorrem em seu ambiente".

A oportunização de convívio entre crianças com seus pares, em ambientes diversos, desde os primeiros anos de vida, tende a multiplicar as possibilidades de açóes em tarefas variadas, viabilizando a aprendizagem por meio da construçáo de significados compartilhados (VERBA, 1994; CARVALHO; IMPÉRIO-HAMBURGER; PEDROSA, 1998; SCHILLING; CLIFTON, 1998; PEDROSA; ECKERMAN, 2000; PEDROSA; CARVALHO, 2009). Pesquisas revelam que a aprendizagem, por meio da interaçáo social, pode ocorrer em crianças que ainda não dominam a fala, isso porque na construção de significados compartilhados, as açóes repetidas dos parceiros ou delas próprias também exercem um papel no desenvolvimento da criança por meio da imitação que ocorre no grupo de pares (NADEL; BAUDONNIĒRE, 1981; PEDROSA; CARVALHO; IMPÉRIO-HAMBURGER, 1997).

Para Hartup $(1989,1996)$, conhecimentos adquiridos por meio da interação, na infância, geram benefícios diversos, contribuindo especialmente para que os comportamentos aprendidos sejam lapidados, de forma a proporcionar um melhor engajamento da criança em atividades sociais. No entanto, pesquisadores atentam à necessidade de se ponderar que estes relacionamentos devem ocorrer em contextos favoráveis a trocas e promoçáo de comportamentos, gerados pela oportunidade de convivência (CAMARGO; BOSA, 2009; CAMARGO; BRONFENBRENNER, 2011; CAMARGO; BOSA, 2012; SANINI, SIFUENTES; BOSA, 2013; WHALON; HANLINE, 2013; LEMOS; SALOMÃO; AGRIPINO-RAMOS, 2014)

A importância do contexto é um dos aspectos enfatizados na Teoria Bioecológica, que pode ser articulada com as noções dos teóricos da interação social. Segundo Bronfenbrenner (2011, p.46), o processo de desenvolvimento humano ocorre por meio de interaçóes recíprocas entre um "[...] organismo humano biopsicológico em atividade e as pessoas, objetos e símbolos existentes no seu ambiente externo imediato". Neste sentido, para avaliar a qualidade das interaçóes, enquanto promotoras do desenvolvimento, as experiências devem considerar tanto aspectos biopsicológicos da pessoa, quanto do ambiente.

É vasta a literatura que associa as características contextuais com o desenvolvimento das pessoas, destacando-se ambientes nos quais se executam atividades musicais estruturadas e/ ou em grupo (JOLY, 2003; EUGENIO; ESCALDA; LEMOS, 2012; RIBEIRO; SANTOS, 2012; SALVADOR, 2013). Evidências têm demonstrado que estes se constituem contextos geradores de habilidades motoras, auditivas, linguísticas, cognitivas, visuais, sociais, entre outras (BRÉSCIA, 2011; CHIARELLI; BARRETO, 2005; OLIVEIRA et al., 2012). 
Segundo Chiarelli e Barreto (2005), a exploração de atividades musicais visando a musicalização para crianças contribuem não somente para a aquisição desta arte, mas para o desenvolvimento global. A partir desta pode-se promover o equilíbrio emocional, a socialização, bem como auxiliar no desenvolvimento da linguagem e da capacidade inventiva, contribuindo em aspectos como expressividade, coordenação motora e motricidade fina, e evoluçôes na percepção sonora e espacial, raciocínio lógico e matemático, estética, apreciação do som e o fazer e criar musical (BERTOLUCHI, 2011).

Os benefícios da educação musical e de atividades envolvendo a música são visíveis, incluindo as crianças com dificuldades de aprendizagem, de comunicação, dificuldades sensoriais e com comprometimentos sociais, incluindo aquelas que se encontram dentro do Transtorno do Espectro do Autismo (TEA) (CHIARELLI; BARRETO, 2005; HOURIGAN; HOURIGAN, 2009; NASCIMENTO, 2013; EUGENIO; ESCALDA; LEMOS, 2012; SANTO, 2012; OLIVEIRA et al., 2012; RODRIGUES et al., 2011). Entretanto, muitas das publicaçóes tratam destes possíveis benefícios no contexto da musicoterapia (KERN; ALDRIDGE, 2006; KIM; WIGRAM; GOLD, 2008; GATTINO, 2009; LIM; DRAPER, 2011; KALAS, 2012) e pouco se tem escrito sobre a educação musical, enquanto contexto de inclusão.

De acordo com o DSM-V, Diagnostic and Statistical Manual of Mental Disorders (APA, 2013), o TEA tem origem precoce e caracteriza-se por déficits na comunicação, interação e reciprocidade social. Além desta tríade, observa-se a presença de padróes repetitivos de comportamentos, interesses ou atividades; condutas comunicativas náo verbais para manutenção e compreensão das relaçóes; bem como, a ocorrência de comprometimento sensorial, característica esta trazida pela primeira vez nesta edição do DSM. Estudo de Elsabbagh et al. (2012) aponta prevalência global de 62 pessoas diagnosticadas com TEA em uma população de 10.000. Já no Brasil, Paula et al. (2011), indicam a proporção de 27,2/10.000, número inferior ao encontrado por estudos internacionais o que, segundo os autores, pode ser atribuído a pouca abrangência da pesquisa, não havendo, portanto, estimativas confiáveis em nosso país. De qualquer modo, estes dados mostram que o número de crianças com TEA é cada vez maior, demandando açóes inclusivas urgentes, nas escolas.

Para Amato (2006), muitos comportamentos considerados não-funcionais podem, na verdade, representar tentativas de interação social. Embora as dificuldades marcantes do quadro, perfis diferenciados de pessoas com TEA são encontrados devido às diferenças sintomatológicas e de desenvolvimento (CZERMAINSKI; BOSA; SALLES, 2013), sendo possível, por exemplo, observar crianças com quadros marcados por fala e/ou gestos preservados, e outras com pouca expressão ou intenção comunicativa verbal ou não verbal. O TEA trata-se, portanto, de um espectro de condiçóes, sendo fundamental considerar tal variabilidade, bem como as características pessoais, contextuais e culturais a fim de se compreender as evoluçôes desenvolvimentais de crianças com este transtorno.

Assim como ressaltado anteriormente, ganhos desenvolvimentais podem ser observados em crianças com TEA, quando em contato com atividades que envolvem a música. Dentre estes alcances, destacam-se: a socialização e apreensão de comandos (KERN; ALDRIDGE, 2006); o aumento de comportamentos dirigidos, tais como: contato visual, iniciativas de envolvimento interativo e atenção conjunta (KIM; WIGRAN; GOLD, 2008); o desenvolvimento 
de aspectos cognitivos, afetivos e motores, a comunicação verbal e não verbal (RODRIGUES, 2011; MIRANDA; MATOS; SILVA, 2013); o aumento qualitativo na execução instrumental, qualidade do som, e interação social (RODRIGUES et al., 2011); o alcance de maior independência, iniciativa de socialização e de ações cotidianas no ambiente escolar; a interação com o grupo e o avanço no processo simbólico relacionado ao conteúdo musical; bem como melhorias na afinação e no acompanhamento rítmico e de percepção (SOARES, 2012).

Considerando os possíveis benefícios da educação musical para a interação social de crianças com TEA, o presente estudo investigou a ocorrência de indicadores de sociabilidade (iniciativas e respostas) de crianças com esse transtorno, em relação a seus pares, durante aulas de percussão infantil, ao longo de três meses.

\section{Método}

\subsection{Participantes}

Participaram da pesquisa dois meninos, com idades de seis (Participante 1 - Alex) e cinco anos (Participante 2 - Marcelo), ambos diagnosticados com Transtorno Global do Desenvolvimento (TGD), CID F-84 (Autismo Infantil). As crianças cursavam o Jardim I em escolas privadas de ensino regular, da cidade de Belém do Pará e foram convidadas para participar de aulas de percussão, em uma Escola de Música na qual a coleta foi realizada. Os participantes pertenciam a turmas diferentes de percussão infantil (Turma A e Turma B), porém heterogêneas, sendo composta cada uma por 10 crianças, das quais cinco se encontravam dentro do Transtorno do Espectro do Autismo (TEA) e cinco sem quaisquer transtornos crônicos. Os critérios de inclusão para as crianças com TEA nas aulas foram: a) ter diagnóstico e laudo clínico do transtorno; b) idades entre cinco e nove anos; c) comprovação de matrícula em escola de ensino regular; d) ausência de histórico de aprendizado musical; e, e) permissão do responsável para participação na pesquisa através da assinatura do Termo de Consentimento Livre e Esclarecido (TCLE). Das 10 crianças com TEA que participaram das aulas de percussão (somando-se as turmas A e B), foram selecionadas para o presente estudo as duas que apresentaram maior frequência nas aulas e que possuíam registros audiovisuais com boa qualidade de imagem e som, o que permitiu a análise pretendida.

\subsection{INSTRUMENTOS}

A Ficha de dados sociodemográficos e de desenvolvimento (BOSA, 2007) foi utilizada para caracterização do perfil desenvolvimental das crianças com TEA, por meio de entrevistas com os responsáveis. Para o registro dos comportamentos sociais foi utilizado o Protocolo de observação de comportamentos de crianças com Transtorno do espectro autista (TEA) com seus pares - POCCTEA/Pares (NASCIMENTO, 2013), composto por 22 itens. O Quadro 1 apresenta exclusivamente a definiçáo operacional dos itens do protocolo que foram registrados neste estudo (8 itens). 


\begin{tabular}{|c|c|}
\hline $\begin{array}{l}\text { Itens/ POCCTEA/Pares } \\
\text { (SIGLA) }\end{array}$ & Definiçáo operacional \\
\hline $\begin{array}{l}\text { Iniciativa funcional espon- } \\
\text { tânea com estereotipias } \\
\text { (IFECE) }\end{array}$ & $\begin{array}{l}\text { A criança com TEA inicia (ou, inicia e mantém) comportamentos funcionais } \\
\text { com os pares, espontaneamente, através de estereotipias (e.g. flaps, pulos, etc.). A } \\
\text { criança utiliza formas pouco convencionais para tentar se aproximar das outras } \\
\text { crianças, durante momento livre ou atividade solicitada pelo Professor, no } \\
\text { entanto, este comportamento permite a interaçáo com os pares. }\end{array}$ \\
\hline $\begin{array}{l}\text { Iniciativa funcional es- } \\
\text { pontânea sem estereotipias } \\
\text { (IFESE) }\end{array}$ & $\begin{array}{l}\left.\text { A criança com TEA inicia }{ }^{1} \text { (ou, inicia e mantém) }\right)^{2} \text { comportamentos funcionais } \\
\text { com os pares, espontaneamente, sem a emissáo de estereotipias (e.g. flaps, pulos, } \\
\text { etc.). A iniciativa se dá por meio de comportamento verbal/não verbal da crian- } \\
\text { ça com TEA, direcionado a outra criança, durante momento livre ou atividade } \\
\text { solicitada pelo professor. }\end{array}$ \\
\hline $\begin{array}{l}\text { Iniciativa funcional } \\
\text { auxiliada sem estereotipias } \\
\text { (IFASE) }\end{array}$ & $\begin{array}{l}\text { A criança com TEA inicia (ou, inicia e mantém) comportamentos funcionais } \\
\text { com os pares, com ou a partir do auxílio físico e/ou verbal de outros (e.g. cuida- } \\
\text { dor, monitor, professor, colega de classe), não havendo a presença de comporta- } \\
\text { mentos marcados por estereotipias. }\end{array}$ \\
\hline $\begin{array}{l}\text { Iniciativa não funcional } \\
\text { concorrente à tarefa sem } \\
\text { estereotipias (INFCTSE) }\end{array}$ & $\begin{array}{l}\text { A criança com TEA emite comportamentos espontâneos, sem estereotipias } \\
\text { (e.g. flaps, pulos, etc.), porém concorrentes à realizaçáo da tarefa solicitada pelo } \\
\text { Professor, dificultando assim a execuçáo das atividades em pares. }\end{array}$ \\
\hline $\begin{array}{l}\text { Resposta funcional espon- } \\
\text { tânea com estereotipias } \\
\text { (RFECE) }\end{array}$ & $\begin{array}{l}\text { A criança com TEA responde espontaneamente, a comportamentos iniciados } \\
\text { por outras crianças, emitindo comportamentos marcados por estereotipias (e.g. } \\
\text { flaps, ecolalia, pulos, etc.), durante momento livre ou atividade solicitada pelo } \\
\text { professor, permitindo a interação. Ainda que por meio de comportamentos } \\
\text { pouco convencionais de resposta observa-se que tais comportamentos permitem } \\
\text { a interaçáo com os pares. }\end{array}$ \\
\hline $\begin{array}{l}\text { Resposta funcional espon- } \\
\text { tânea sem estereotipias } \\
\text { (RFESE) }\end{array}$ & $\begin{array}{l}\text { A criança com TEA responde espontaneamente, sem a emissão de estereotipias } \\
\text { (e.g. flaps, pulos), a comportamentos iniciados por outras crianças (com tea ou } \\
\text { típicas), através de comportamento verbal/não verbal (e.g. PECS, contato visual, } \\
\text { sorriso, ou gestos direcionados ao outro), durante momento livre ou atividade } \\
\text { solicitada pelo Professor, de forma a permitir a interação. }\end{array}$ \\
\hline $\begin{array}{l}\text { Resposta não funcional de } \\
\text { afastamento sem estereoti- } \\
\text { pias (RNFASE) }\end{array}$ & $\begin{array}{l}\text { A criança com TEA responde espontaneamente a comportamentos iniciados } \\
\text { por outras crianças, afastando-se destas, sem a emissáo de comportamentos } \\
\text { marcados por estereotipias (e.g. flaps, pulos, fala repetitiva, etc.) ou mantendo-se } \\
\text { na tarefa que está executando, sem se direcionar ao colega. }\end{array}$ \\
\hline $\begin{array}{l}\text { Resposta não funcional } \\
\text { concorrente à tarefa sem } \\
\text { estereotipias (RNFCTSE) }\end{array}$ & $\begin{array}{l}\text { A criança com TEA responde espontaneamente a comportamentos iniciados por } \\
\text { outras crianças, sem a emissão de estereotipias (e.g. flaps, pulos, fala repetitiva, } \\
\text { etc.), porém concorrentes à realizaçáo da tarefa solicitada pelo Professor. }\end{array}$ \\
\hline
\end{tabular}

Quadro 1 - Definiçóes operacionais dos itens do POCCTEA/Pares registrados neste estudo.

Fonte: Nascimento (2013, p. 81-86)

\subsection{Procedimentos para coleta de dados}

O estudo foi aprovado pelo Comitê de Ética em Pesquisa em Seres Humanos - CEPICS/UFPA, do Instituto de Ciências da Saúde da Universidade Federal do Pará, sob o protocolo $n^{\circ} 102 / 11$. Para a coleta de dados, inicialmente, realizou-se entrevista com os responsáveis das crianças com TEA, interessados em matriculá-las na oficina. Nesta ocasião foi apresentado o objetivo e Termo de Consentimento Livre e Esclarecido (TCLE) da pesquisa e todos que concordaram em participar do estudo o assinaram, sendo, posteriormente, preenchida a Ficha de dados sociodemográficos e de desenvolvimento (BOSA, 2007). Após consentimento das famílias, as aulas de percussão infantil iniciaram, ocorrendo duas vezes por semana, com duração 
de aproximadamente 30 minutos cada, no período de três meses. A sala de aula era estruturada contando com oito tatames dispostos no chão de forma a permitir que a turma sentasse em círculo. Uma estante fixada na parede servia para guardar os equipamentos gerais (parte superior) e os instrumentos e cestas (parte inferior). A assepsia do tatame era feita com álcool antes e após cada aula. Um quadro negro médio foi utilizado para confeccionar o mural de chamada. Velcros foram fixados neste e em fichas (aprox. 20x8cm), de papelão revestido com papel A4 (contendo impressáo com nome + uma foto da criança, com aprox. 6x8cm), as quais foram recobertas, posteriormente, com papel adesivo transparente. Nas aulas foram utilizados quatro instrumentos musicais (tambor de plástico; ganzá, coquinho e claves, de madeira). Uma cesta de plástico pequena era utilizada para acomodar cada grupo de três instrumentos (ganzá, coquinho e clave). A cesta com instrumentos era exposta, em frente a criança e o tambor ficava em frente a cesta. Cada grupamento de instrumentos, bem como as cestas tinham cores semelhantes. O primeiro passo da aula consistia em solicitar as crianças que retirassem seus calçados, auxiliando somente aquelas cujos pais demarcaram ter dificuldades. Durante as aulas eram desenvolvidas seis atividades.

Atividade 1: utilização da música "Olá Maria” (autor desconhecido). O professor, juntamente com os colegas de turma, cantava a música e cada aluno deveria pegar uma das fichas (com sua foto nome) quando chamado, e fixar no mural. As fichas eram dispostas no chão, em frente ao quadro que ficava apoiado na parede;

Atividade 2: utilização da música "Quem sabe fazer um som assim" (autor desconhecido). A professora inicialmente mostrava aos alunos a melhor forma de manusear (segurar, tocar) cada instrumento. Durante momentos diferentes da música era realizada a troca de instrumentos (clave, ganzá, tambor e coquinho), indicada pelo comando da professora, e os alunos deveriam fazê-la retirando-os da cesta e mantendo o ritmo que acompanhava a canção. No segundo momento, por sua vez, o aluno deveria improvisar um ritmo no instrumento, para que os demais repetissem. E, no terceiro momento, cada criança escolheria um instrumento, o qual deveria ser executado juntamente com os colegas;

Atividade 3: utilização da música "Garibaldi" (autor desconhecido). Inicialmente a professora direcionava os alunos em como manusear (segurar, tocar) o coquinho. Ao cantar a música os alunos deveriam pegar o instrumento que estava dentro da cesta e percutir o mesmo ritmo proposto pela professora (forte, fraco) e posicionamento do instrumento (com cavidade para dentro ou fora), entoando ao mesmo tempo a canção;

Atividade 4: utilização da música "Passa, passa gaviaao" (autor desconhecido). Os alunos e a professora deveriam estar dispostos em pé, de mãos dadas em um círculo. Quando canção iniciava todos deveriam se movimentar na direção escolhida pela Professora. Em cada refrão, as crianças repetiriam os movimentos corporais, sugeridos (ex. bater palmas; bater os pés; imitar o som da serpente; descer lentamente até o chão), girando conjuntamente o corpo. A criança deveria mudar de local após cada execução de movimento e dar as mãos a outra pessoa;

Atividade 5: utilização da música "Contente" (Tia Edna Mattos). Os alunos deveriam estar de pé dispostos lado a lado em formato de círculo. Ao cantar a música, a professora deveria gesticular com o corpo movimentos sugeridos pela música e as crianças deveriam caminhar pela sala enquanto realizavam os comandos (exceto o abraço). No momento do abraço era 
necessário atentar para que tal comportamento não fosse direcionado a uma única pessoa, por isso era necessário que as crianças caminhassem pela sala;

Atividade 6: utilização da canção “Tchau! Tchau! Tchau” (Gláucia Freire). Para esta atividade os alunos deveriam estar sentados dispostos em círculo. Ao cantar a música, a professora deveria gesticular com as mãos o signo de "tchau", indicando para os alunos o término da aula. A melodia era repetida três vezes e a professora solicitava que os alunos fizessem os mesmos movimentos de "tchau". Após este momento, era solicitado as crianças que calçassem seus sapatos, sendo auxiliadas as que necessitavam. Como a aula ocorria em um andar superior, cada criança era acompanhada pelos monitores para descer a escada, sendo entregues diretamente aos responsáveis. Na turma do participante 1 foram ministradas 17 aulas, das quais este participou de oito. Já na turma do participante 2 foram ministradas 23 aulas, das quais este participou de 12. Para este estudo foram analisadas somente oito aulas de cada participante, de acordo com a presença destes e qualidade dos registros. As aulas foram videogravadas por meio de três câmeras marca JVC (Everio 45X Dinamic Zoom), dispostas estrategicamente. Além dos alunos, estiveram presentes na sala, em cada aula: uma monitora, dois professores, uma psicóloga e, esporadicamente os responsáveis pelas crianças/TEA. A presença dos últimos era permitida de acordo com a necessidade da criança (agitação intensa, dificuldade de condução em sala).

\subsection{Procedimento para análise dos dados}

As informações coletadas pela Ficha de dados sociodemográficos e de desenvolvimento (BOSA, 2007) foram organizadas, descritivamente, elencando-se, para efeitos de identificação de perfil dos participantes, somente os dados respondentes às quatro áreas de desenvolvimento que tendem a estar mais comprometidas no TEA: comunicação, interação social, comportamento e processamento sensorial. Posteriormente realizou-se a análise dos registros das videogravaçóes das aulas de Percussão, por meio do POCCTEA/Pares, contabilizando-se a frequência dos itens deste instrumento, em cada uma das aulas. No total, a análise contou com 240 minutos de videogravação, por participante, correspondentes a oito aulas (não consecutivas), de 30 minutos cada. Foram realizados recortes das cenas em formato audiovisual de todas as aulas, considerando-se somente os episódios de orientação da criança com TEA em direção a seus pares (típicos ou com TEA) e vice-versa, independente de contato físico. No total, 39 cenas foram analisadas, sendo 20 do participante 1 (Alex) e 19 do participante 2 (Marcelo). As cenas foram transcritas e dispostas em um documento do Word para facilitar a classificação. Deve-se ressaltar que uma cena poderia conter mais de uma categoria do protocolo. $\mathrm{O}$ material (DVD com recortes das cenas interativas + documento do Word com a descrição destas) serviu de suporte para o preenchimento do POCCTEA/Pares, contabilizando-se a frequência dos comportamentos transcritos. Destaca-se que a contabilização dos comportamentos deu-se em termos de frequência total dos itens do instrumento por aula, para cada caso, sendo realizada estatística descritiva com auxilio do programa Excel. Para fins de ilustração dos comportamentos codificados, algumas cenas transcritas são apresentadas, nos resultados. Os itens do POCCTEA/Pares que não foram registrados durante a coleta de dados, não compóem os resultados (Figuras 1 e 2 ), uma vez que obtiveram frequência igual a zero $(f=0)$. 


\section{Resultados}

\subsection{Estudo de caso (Participante 1- Alex)}

Perfil comportamental e desenvolvimental: conforme relato dos pais, verificou-se que Alex, apesar de suas dificuldades, apresentava comunicação marcada pela presença de imitação social apropriada; boa compreensão de instruçôes verbais; variação na expressão facial e de respostas em diferentes contextos. Quanto à interação social, aceitava contato físico (pegar a máo, abraços, auxílio para andamento e conclusão de tarefas); apresentava reciprocidade social ou emocional ocasional (iniciativa de aproximação; participação ativa em atividades); não ignorava pessoas ou crianças (conhecidas ou desconhecidas) e buscava espontaneamente o outro a fim de compartilhar (ex. mostrando, trazendo ou apontando para objetos). No entanto, a procura por outras pessoas ocorria, na maioria das vezes, em situaçôes nas quais o propósito era pedir/ solicitar algo, geralmente utilizando os outros como "se fossem instrumentos" a fim de conseguir o que desejava e não propriamente para interagir socialmente.

No que compete ao comportamento, não possuía apego a rotinas; seguia regras e comandos simples; aceitava auxílio para execução de tarefas; apresentava agitação intensa (correr, gritar, pular); pouca frequência de estereotipias motoras (flaps); e pouca tolerância à frustraçáo, em episódios esporádicos (quando contrariado, costumava: irritar-se, caminhar e murmurar pelos ambientes nos quais se encontrava). Já quanto ao Processamento sensorial, foi relatada ausência de interesse incomum por propriedades sensoriais de objetos; e presença de reaçóes adversas a sons (exclusivo para barulho intenso - reagia cobrindo os ouvidos com as mãos).

No que se refere aos resultados encontrados por meio do POCCTEA/Pares, a Figura 1 mostra as distribuiçóes de frequência de Comportamentos funcionais e não funcionais por categoria, em cada uma das oito aulas de educação musical. Santo (2011), autora do Protocolo de Observação do Comportamento de crianças com TEA no contexto de Educação musical (Percussão), instrumento do qual o POCCTEA/Pares foi derivado, faz uso destes termos, atrelando e adaptando-os aos significados propostos dentro da área de linguagem/comunicação (WETHERBY; 1984; STONE et al., 1997), onde, a exemplo do termo comunicação funcional, comportamentos funcionais remete-se a apresentação de condutas que levam a execução de uma atividade/função, de forma a permitir a interação com o outro; e comportamentos não funcionais, a exemplo da comunicação não-funcional, refere-se a condutas que impedem ou dificultam a execução de uma atividade/função, bem como a interação com o outro. 


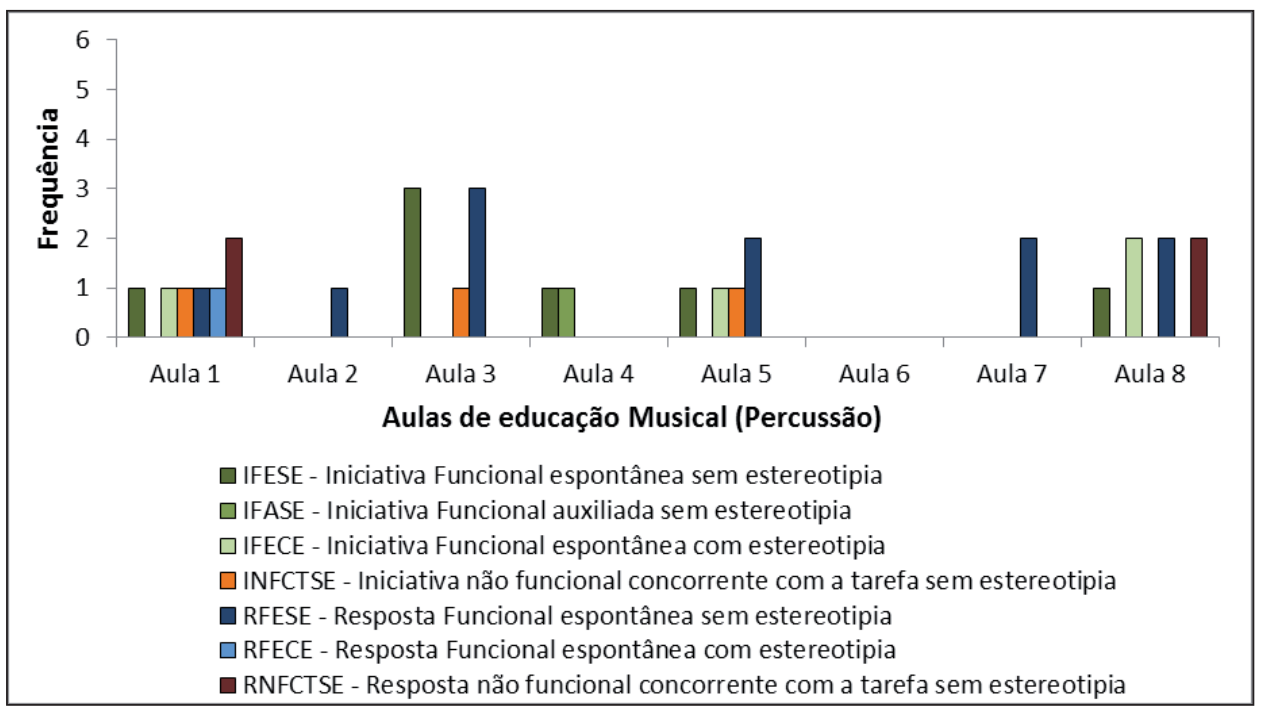

Figura 1 - Frequência de iniciativas e respostas (funcionais e não funcionais) com pares no transcurso/decorrer de oito aulas de educação musical (Percussão) - Participante 1. Fonte: elaboração própria.

Analisando-se o curso das aulas, na Figura1, observa-se que as iniciativas funcionais espontâneas, sem estereotipias (IFESE), tiveram aumento e estabilização a partir da quarta aula de aulas analisadas, curso alterado com diminuição registrada durante as $6^{\mathrm{a}}$ e $7^{\mathrm{a}}$ aulas. Este declínio pode ser explicado, possivelmente, pelo fato do aluno ter se mostrado indisposto, sendo assessorado integralmente pelos responsáveis. O comportamento auxiliado, por sua vez, apresentou somente uma ocorrência (IFASE, $f=1$ ), na quarta aula analisada. As descriçóes que se seguem ilustram a transcrição de alguns dos comportamentos.

A Professora pede que Alex dê a mão à colega ao lado, Alex estende a mão à colega, que não a pega de imediato ${ }^{1}$. Alex oferece novamente a mão à colega, porém espontaneamente ${ }^{2}$, entretanto, Alex muda de local e fica entre a professora e uma mãe (Escola de Música, Aula 4, IFASE ${ }^{1}, I F E S E^{2}$ )

Como se pode ver na figura 1 , registrou-se ainda, baixa frequência de comportamentos marcados por estereotipias tanto para iniciar interaçóes (IFECE, $f=2$ ) quanto para respondê-las (RFECE, $f=1$ ).

Uma colega da alguns pulinhos, Alex está de mãos dadas com a professora, dá pulinhos e olha para a colega, esta dá alguns pulinhos, depois se aproxima de Alex, estendendo a mão a ele, Alex estende sua mão e segura a mão da colega, e ambos começam a pular juntos de mãos dadas e, depois, soltam as mãos (Escola de Música, Aula 3, IFECE)

Alex está dando pulinhos não direcionados aos colegas. Um colega e a Professora seguram Alex pela máo no momento da atividade em roda. Alex aceita ser segurando e segue o sentido da roda dando pulinhos, embora se mantenha de mãos dadas com o colega e a Professora (Escola de Música, Aula 1, RFECE)

$\mathrm{O}$ registro de iniciativas não funcionais, restringiu-se a modalidade concorrente à execução de tarefa. As iniciativas não funcionais ocorreram nas $1^{\mathrm{a}}, 3^{\mathrm{a}}$ e $5^{\mathrm{a}}$ aulas (INFCTSE, $f$ $=1 /$ cada aula). 
Alex está de mãos dadas com o colega e segue o sentido da roda, caminhando conforme as outras crianças, continuando a atividade proposta "Pés no chão tem som assim". Ao ser cantado "Bater palmas tem som assim", Alex solta sua máo da do colega e da Professora, e se direciona ao centro da roda onde fica parado e, logo após dá pulinhos, porém náo direcionados aos colegas em roda. Ao se cantar "passa, passa..." (momento de ficar de máos dadas) Alex ainda se encontra dentro da roda (Escola de Música, Aula 1, INFCTSE)

Já as respostas náo funcionais, apresentaram somente quatro ocorrências, registradas na primeira e na última aula, exclusivamente, na modalidade concorrente à tarefa (RNFCTSE, $f=2 /$ cada aula), conforme abaixo:

Alex é chamado pela lista de frequência para colocar seu nome no quadro, a professora tenta levantá-lo, um colega diz "Vai", o empurrando para levantar. A professora insiste, mas Alex não sai do lugar, o mesmo colega vai por trás de Alex, o empurra e diz "vai", enquanto o colega que está ao lado de Alex também se aproxima. Alex permanece no local pegando a baqueta do tambor (Escola de Música, Aula 1, RNFCTSE)

\subsection{Estudo de caso (Participante 2 - Marcelo)}

Perfil comportamental e desenvolvimental: a entrevista com os pais revelaram que, quanto à Comunicação, Marcelo é uma criança não-verbal, porém com expressão emocional adequada ao contexto e com dificuldades na imitaçáo social e na compreensão da linguagem verbal. Em relação à interação social, apresentava prejuízo no contato visual direto e, geralmente, obtinha o que desejava sem esboçar gestos antecipatórios. Apresentava pouca dificuldade em desenvolver relacionamentos com seus pares (abraçava, beijava e aceitava contato), sendo verificada reciprocidade social de forma ocasional (respostas e iniciativas sociais com outras crianças, bem como engajamento em tarefas simples). Quanto ao comportamento, Marcelo apresentava estereotipias motoras (especialmente o bater palmas de forma repetitiva; movimentar das mãos próximas do rosto; e, flaps), bem como agitaçâo e dificuldades na coordenação motora ampla (correr, pular, chutar, pedalar); Além disso, a criança seguia comandos simples e possuía apego à rotina, porém sem exigência de sequências fixas. Segundo os responsáveis, Marcelo apresentava heterolesão (quando contrariado mostrava-se agressivo com os outros, embora em nível moderado). Possuía sensibilidade sensorial a sons específicos (ex. furadeira, canto do galo, etc.).

Quanto aos Comportamentos funcionais e não funcionais registrado através do POCCTEA/Pares, a frequência de iniciativas e respostas do participante 2, durante as aulas de educação musical, está apresentada na Figura 2. 


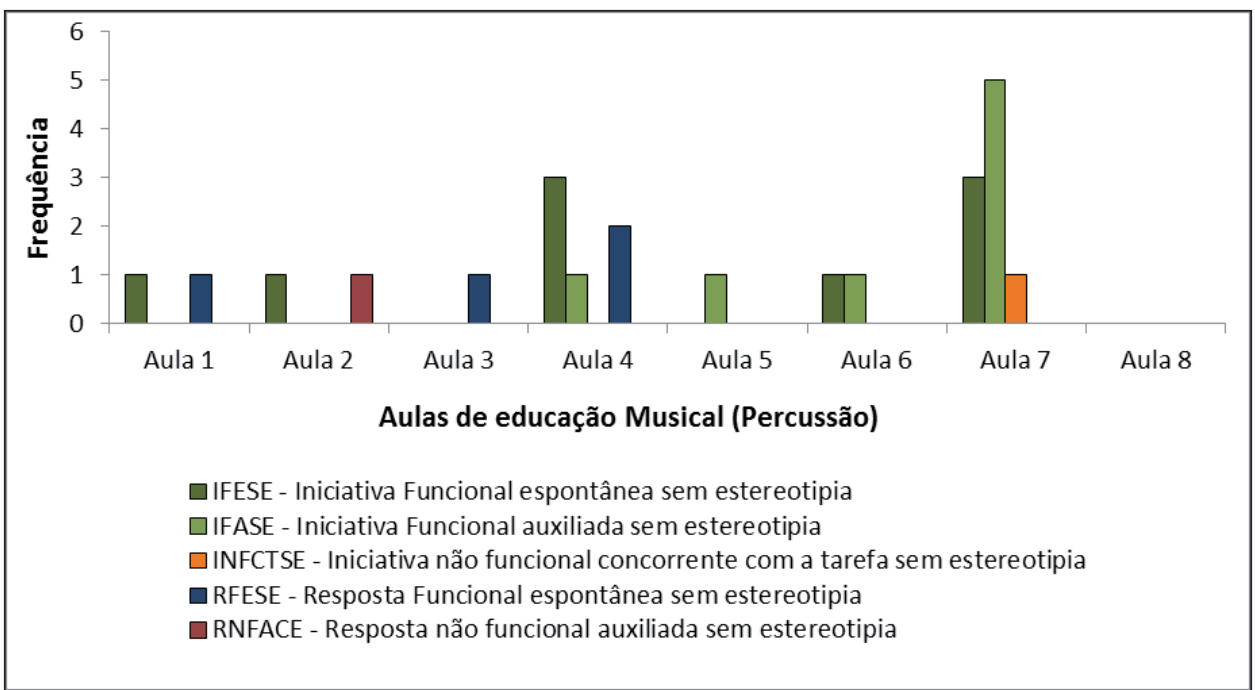

Figura 2 - Frequência de iniciativas e respostas (funcionais e não funcionais) com pares no transcurso/decorrer de oito aulas de educação musical (Percussão) - Participante 2.

Fonte: elaboração própria.

Analisando-se o curso das aulas, observa-se que as iniciativas funcionais apresentadas por Marcelo ocorreram espontaneamente e com a ausência de estereotipias (IFESE) até a quarta aula, a partir da qual iniciou-se o registro de Iniciativas auxiliadas (IFASE).

No momento em que é para dar as mãos ao colega, na atividade de roda, a professora pega na mão de Marcelo, que ao voltar à roda oferece a mão a um colega, porém este náo o vê e logo é demandado 'pra parar se pára assim'. (Escola de Música, Aula 1, IFESE)

A partir da aula 4, foi verificado o auxílio do monitor (IFASE) a fim de promover ou manter a interação de Marcelo com seus pares. Estas ocorrências se deram tanto verbalmente, quanto por contato físico.

No momento em que é para formar a roda para iniciar a atividade "passa, passa...", ao observar que Marcelo não se aproxima, a professora solicita à turma que se dêem as mãos para iniciar a atividade da roda, Marcelo entäo caminha pela sala e vai em direção a um colega estendendo a mão a ele, no entanto o colega não ver de imediato e sai da roda (Escola de Música, Aula 4, IFASE)

A Professora tenta colocar Marcelo ao lado de uma colega, auxiliando com que pegue em sua mão. Ambos seguram as mãos e seguem o sentido da roda de mãos dadas, até ser demandado "Se você está contente bata palma". (Escola de Música, Aula 6, IFASE)

As respostas funcionais, por sua vez, ocorreram exclusivamente na modalidade espontâneo (RFESE=4).

Quando é demandado, no momento da roda, que deem as mãos, um colega estende a mão a Marcelo, que segura e segue o sentido da roda de mãos dadas com o colega (Escola de Música, Aula 2, RFESE) 
Os comportamentos não funcionais obtiveram uma baixa frequência, sendo registradas somente duas emissóes: uma iniciativa não funcional na modalidade concorrente com a tarefa (INFCTSE) e uma resposta não funcional para fins de afastamento do outro (RNFACE).

Marcelo solta a mão do colega antes do momento de fazê-lo e depois tenta voltar a pegá-la, porém este não a pega, visto que já passara o momento de ficar de mãos dadas e é o momento no qual devem fazer o movimento de serpente com as mãos de acordo com a música "a serpente faz assim". (Escola de Música, Aula 7, INFCTSE)

É demandado que as crianças se deem as mãos na atividade de roda, Marcelo estende a mão ao colega, que também a estende simultaneamente. Ambos seguram as mãos, seguindo de mãos dadas o sentido da roda, mas Marcelo solta a máo do colega antes do momento indicado pela professora e fica parado de mãos para cima. (Escola de Música, Aula 7, RNFACE)

\section{Discussāo}

Durante as aulas de educação musical pode-se observar que ambos os participantes, apresentaram interação social com pares, marcada por tendência ao aumento de iniciativas e respostas espontâneas e à diminuição de comportamentos não funcionais. Verificou-se nestes ainda, a presença de comportamentos marcados pelo uso de estereotipias possivelmente como tentativas de/e interaçóes, embora esporadicamente, e a baixa frequência de comportamentos não funcionais.

No que se refere ao primeiro caso (Alex), acredita-se que a indisposição do participante na $\sigma^{\mathrm{a}}$ aula e o acessoramento nesta, por meio dos responsáveis, podem ter sido fatores importantes para o declínio de iniciativas funcionais nas Aulas 6 e 7. A extinção das respostas espontâneas com o uso de estereotipias (RFECE), foi seguida pelo aumento das sem estereotipias (RFESE). No entanto, deve-se ressaltar que embora este aumento revele que o contexto de educação musical foi favorável a manutenção deste comportamento, outras condutas funcionais (IFESE) foram afetadas, tendo sua frequência diminuída dada a configuração de manejo comportamental utilizado pelos adultos.

No caso do participante 1, a ocorrência de comportamentos funcionais marcados por estereotipias (IFECE, RFECE), embora com baixa frequência, mostraram que esta característica, própria ao transtorno, auxiliou Alex a aproximar-se do outro (pares), permitindo assim a interação. Este resultado corrobora com Gallardo (2004), o qual afirma que a presença de estereotipias, em pessoas com TEA, também pode marcar uma forma de comunicação. Neste estudo, a estereotipia parece ter funcionado como uma forma de comunicação gestual que permitiu ao participante interagir com o outro. Nesse sentido, assim como ressaltado por Filho e Cunha (2010), é importante se verificar sempre as intençóes comunicacionais reveladas por meio de sinais comunicativos diversos, considerando-se o contexto nas quais ocorrem. Logo, as estereotipias, neste estudo, também puderam ser verificadas enquanto comportamento funcional, permitindo a interação entre pares.

No caso do segundo participante (Marcelo), pode-se verificar a partir da Aula 4 a ocorrência de comportamentos auxiliados (IFASE), seguido pela diminuição e extinção de comportamentos funcionais (respectivamente IFESE e RFESE). Na Aula 7, por sua vez, embora tenha sido verificado o aumento de auxílio dos monitores (IFASE), as oportunidades da criança realizar as atividades/comandos sozinha também aumentaram, gerando assim mais 
iniciativas espontâneas (IFESE). Já na aula 8, por sua vez, não houve emissóes de quaisquer comportamentos com pares, visto que nesta, a criança teve auxílio total de duas monitoras, não sendo observadas oportunidades da criança iniciar ou completar quaisquer atividades sozinha, bem como interagir com pares. Estes dados sugerem que embora o relacionamento com adultos seja promotor de desenvolvimento, auxiliar integralmente a criança em atividades as quais esta já possui capacidade de realizar sozinha ou com pouco auxílio, pode impossibilitar seu avanço, bem como restringir suas oportunidades de interação e geração de novos comportamentos a partir de experiências com pares, segundo defende Hartup (1989, 1996). Bronfenbrenner (2011), já ressaltava tal importância deste olhar revelando a necessidade de se atentar paras características da pessoa a fim de melhor compreender o processo de desenvolvimento.

O comportamento dos participantes, enquanto disponíveis e atuantes em iniciativas e respostas funcionais frente aos pares corrobora com Sanini (2011), uma vez que esta última ressalta a presença de habilidades em crianças com TEA, especialmente a responsividade social. Além disso, a manutenção de comportamentos funcionais ao longo das aulas e pouca frequência de comportamentos não funcionais sugerem que as aulas de educação musical podem ser um contexto promissor para a interaçáo social destes alunos. Neste sentido, tais resultados corroboram achados anteriores que mostram que experiências de trabalhos em grupo, especialmente as musicais, podem contribuir para a interação social de crianças com TEA (RODRIGUES et al., 2011; EUGENIO; ESCALDA; LEMOS, 2012; OLIVEIRA et al., 2012; RIBEIRO; SANTO, 2012; SOARES, 2012, SALVADOR, 2013; NASCIMENTO, 2013).

\section{Conclusótes}

A diminuição de iniciativas e respostas não funcionais, bem como o aumento de iniciativas e respostas funcionais com pares, no correr das aulas de educação musical, revela que a participação em uma tarefa estruturada, que permite o trabalho com parceiros de mesma faixa etária, pode contribuir para a aquisição, manutenção e aprimoramento de comportamentos já apresentados pela criança, sendo necessária, entretanto, uma frequência contínua, a fim de que os aprendizados sejam explorados e mantidos.

A ocorrência de comportamentos funcionais marcados por estereotipias mostraram que estes "sintomas", característicos do TEA podem ter uma função comunicativa e permitir a interaçáo e comunicaçáo da criança com TEA e seus pares. Esta relaçáo pode ser melhor explorada em futuros estudos, no contexto educacional.

Destaca-se que a baixa frequência de comportamentos funcionais, durante as aulas analisadas, chamou atenção porque os perfis dos participantes inicialmente apontavam para um maior potencial comunicativo e interativo, nos dois casos. Sobre isso, dados do participante 2 revelaram que o excessivo auxílio do adulto em atividades na sala parece ter interferido na manutenção de interações funcionais deste com seus pares. Contudo, a investigação do comportamento do adulto, neste contexto, precisa ser melhor investigado em outros estudos. Sugere-se que investigações futuras atentem a aspectos do contexto e ao tipo de mediação empregada pelo professor, visando a práticas que, por exemplo, estimulem a autonomia da criança, bem como a formação de pais e profissionais que trabalham com este publico de modo que estes possam identificar os momentos adequados de intervir e de deixar a criança mais livre, contribuindo assim 
para a apresentação de condutas sociais já presentes no repertório comportamental da criança e a realização de atividades, respeitando suas habilidades e limitaçóes, ou seja, quando a mesma deve executá-las sem auxílio ou com auxílio moderado. Acredita-se que ao conhecer o perfil pessoal e comportamental da criança com TEA, possibilitará aos professores/monitores verificar os avanços que a mesma apresenta ou adquire em cada aula, contribuindo para que comportamentos funcionais sejam maximizados, por meio de atividades, e alternativas sejam pensadas frente a comportamentos náo funcionais. Outro aspecto se refere à baixa assiduidade dos participantes com TEA às aulas e o cancelamento de aulas (feriados, adoecimento de membros da equipe, etc.).

Dentre as limitaçôes envolvidas na condução deste estudo está a presença de diferentes adultos nas aulas, visto que se tratava de oficinas e nem sempre foi possível contar apenas com os mesmos professores, em todas as aulas. Do ponto de vista da análise, a inclusão de mais de um avaliador para codificação dos dados observados no contexto, de forma independente, poderia contribuir para o rigor metodológico da pesquisa. Contudo, ressalta-se que se trata de um estudo descritivo, de cunho exploratório e, como tal, parece lançar luzes sobre o potencial da educação musical na inclusão de alunos com TEA, especialmente no que se refere à interação social.

\section{REFERÊNCIAS}

APA. American Psychiatric Association. DSM-V-Diagnostic and statistical manual of mental disorders. 5.ed. Washington: British Library Cataloguing, 2013.

AMATO, C. A. D. L. H. Questóes funcionais e sócio-cognitivas no desenvolvimento da linguagem em crianças normais e autistas. 2006. 165f. Tese (Doutorado em Semiótica e Linguística Geral) Faculdade de Filosofia, Letras e Ciências Humanas, Universidade de São Paulo, São Paulo, 2006.

BERTOlUCHI, M. A. Autismo, musicalização e musicoterapia. Artigo Meloteca. 2011.

BOSA, C. A. Ficha de dados sociodemográficos e de desenvolvimento. Unpublished manuscript, 2007.

BRÉSCIA, V. P. Educação musical: bases psicológicas e ação preventiva. 2.ed. Campinas: Átomo, 2011.

BRONFENBRENNER, U. Bioecologia do desenvolvimento humano: tornando os humanos mais humanos. Porto Alegre: Artes Médicas, 2011.

CAMARGO, S. P. H.; BOSA, C. A. Competência social, inclusão escolar e autismo: revisão crítica da literatura. Psicologia e Sociedade, Belo Horizonte, v.21, n.1, p.65-74, 2009.

CAMARGO, S. P. H.; BOSA, C. A. Competência social, inclusão escolar e autismo: um estudo de caso comparativo. Psicologia Teoria e Pesquisa, Brasília, DF, v.28, n.3, p.315-324, 2012.

CARVALHO, A. M. A.; IMPÉRIO-HAMBURGER, A.; PEDROSA, M. I. Interaction, regulation and correlation in the context of human development: conceptual discussion and empirical examples. In: LYRA, M.C.D. P.; VALSINER, J. (Eds.). Construction of psychological processes in interpersonal communication. Stamford: Ablex, 1998. p.155-180.

CHIARELLI, L. K. M.; BARRETO, S. J. A importância da musicalização na educação infantil e no ensino fundamental: a música como meio de desenvolver a inteligência e a integração do ser. Revista Recre@rte, n.3, 2005.

CZERMAINSKI, F. R.; BOSA, C. A.; SALLES, J. F. Funçôes executivas em crianças e adolescentes com transtorno do espectro do autismo: uma revisão. Psico, Porto Alegre, v.44, n.4, p.518-525, 2013. 
ELSABBAGH, M. et al. Global prevalence of autism and other pervasive developmental disorders. Autism Research, n.5, p.160-179, 2012.

EUGÊNIO, M. L.; ESCALDA, J.; LEMOS, S. M. A. Desenvolvimento cognitivo, auditivo e linguístico em crianças expostas à música: produção de conhecimento nacional e internacional. Revista CEFAC, São Paulo, v.14, n.5, p.992-1003, 2011.

FILHO, J. F. B.; CUNHA, P. A Educação especial na perspectiva da inclusão escolar transtornos globais do desenvolvimento. 2010.

GALLARDO, R. Musicoterapia: 100 preguntas fundamentales y sus respuestas. Buenos Aires: Ediciones Estúdio de Musicoterapia Clínica, 2004.

GATTINO, G. S. A influência do tratamento musicoterapêutico na comunicação de crianças com transtornos do espectro autista. 2009. 119f. Dissertação (Mestrado em Saúde da criança e do adolescentes) - Faculdade de Medicina, Universidade Federal do Rio Grande do Sul, Rio Grande do Sul, Porto Alegre, 2009.

HARTUP, W. W. Social relationships and their development significance. American Psychologist Association, v.44, n.2, p.120-126, 1989.

HARTUP, W. W. The company they keep: friendships and their developmental significance. Child Development, v.67, p.1-13, 1996.

HOURIGAN, R.; HOURIGAN, A. Teaching music to children with autism: understandings and perspectives. Music Educators Journal, v.96, n.1, p.40-45, 2009.

JOLY, I. Z. L. Música e educação especial: uma possibilidade concreta para promover o desenvolvimento de indivíduos. Revista do Centro de Educação, v.28, n.2, p.1-5, 2003.

KALAS, A. joint attention responses of children with autism spectrum disorder to simple versus complex music. Jornal of Music Therapy, v.49, n.4, p.430-452, 2012.

KERN, P.; ALDRIDGE, D. Using embedded music therapy interventions to support outdoor play of young children with autism in an inclusive community-based child care program. The Journal of Music Therapy, v.43, n.4, p.270-294, 2006.

KIM, J.; WIGRAM, T.; GOLD, C. The effects of improvisational music therapy on joint attention behaviors in autistic children: a randomized controlled study. Journal of Autism and Developmental Disorders, v.38, p.1758-1766, 2008.

LEMOS, E. L. M. D.; SALOMÃO, N. M. R.; AGRIPINO-RAMOS, C. S. Inclusão de crianças autistas: um estudo sobre interaçôes sociais no contexto escolar. Revista Brasileira de Educação Especial, Marília, v.20, n.1, p.117-130, 2014.

LIM, H. A.; DRAPER, E. The effects of music therapy incorporated with applied behavior analysis verbal behavior approach for children with autism spectrum disorders. Journal of Music Therapy, v.48, n.4, p.532-550, 2011.

MIRANDA, M. A.; MATOS, M. A. S.; SILVA, R. M. M. A música na educação especial: inclusão de crianças com necessidades educacionais especiais no NEPPD. In: SEMINÁRIO INTERNACIONAL INCLUSÃO EM EDUCAÇÃO, 2013, Rio de Janeiro. Anais eletrônicos... Rio de Janeiro, 2013.

NADEL, J.; BAUDONNIERE, P. Imitação, modo preponderante de intercâmbio entre pares, durante o terceiro ano de vida. Cadernos de Pesquisa, n.39, p.26-31, 1981. 
NASCIMENTO, P. S. Comportamentos de crianças com transtorno do espectro autista com pares nos contextos de educação musical e recreio escolar. 2013. 112f. Dissertação (Mestrado em Teoria e Pesquisa do Comportamento) - Instituto de Psicologia, Universidade Federal do Pará, Pará, Belém, 2013. Disponível em: <http://www.mediafire.com/view/4211xicjmgzq6cp/ Disserta\%C3\%A7\%C3\%A3o+da++Nascimento+P.+S.+\%282013\%29.pdf >. Acesso em: 08 nov. 2013

OLIVEIRA, G. F. et al. Música e inclusão: relato de experiência em uma turma de percussão infantil. In: ENCONTRO REGIONAL NORTE DA ABEM, 6., 2012, Belém. Anais eletrônicos... Belém, 2012. Disponível em: <http://abemeducacaomusical.com.br/sistemas/anais/congressos/ANAIS_VII_ ABEM_REGIONAL_NORTE_BELEM_PA_2012.pdf>. Aceso em: 08 maio 2014.

PAULA C. S. et al. Brief Report: prevalence of pervasive developmental disorder in Brazil: a pilot study. Journal of Autism and Development Disorders, v.41, p.1738-1742, 2011.

PEDROSA, M. I.; CARVALHO, A. M. A.; IMPÉRIO-HAMBURGER, A. From disordered to ordered movement: attractor configuration and development. In: FOGEL, A.; LYRA, M. C. D. P.; VALSINER, J. (Eds.). Dynamics and indeterminism in developmental and social processes Mahwah: LEA, 1997. p.135-151.

PEDROSA, M. I. P. C.; CARVALHO, A. M. A. Aprendendo sobre eventos físicos com parceiros de idade. Psicologia USP, São Paulo, v.20, n.3, p.355-373, 2009.

PEDROSA, M. I.; ECKERMAN, C. O. Sharing means: How infants construct joint action from movement, space, and objects. In: BIENNIAL MEETINGS OF ISSBD, 16., 2000, Beijing. Anais.... Beijing: ISSBD, 2000.

RIBEIRO, F. S.; SANTOS, F. H. Treino musical e capacidade da memória operacional em crianças iniciantes, veteranas e sem conhecimentos musicais. Psicologia Reflexão e Crítica, v.25, n.3, p.59-567, 2012.

RODRIGUES, J. Desenvolvimento global do adolescente com diagnóstico de transtorno autista inserido em turma de educação musical para crianças e adolescentes com e sem o transtorno: um estudo de caso. 2011. 61f. Trabalho de Conclusão de Curso (Especialização) - Departamento de Psicologia, Universidade do Estado do Pará, Belém, 2011.

RODRIGUES, J. C. et al. Educação musical inclusiva: aulas de violoncelo em grupo para crianças e adolescentes com diagnóstico de autismo e sem diagnóstico de transtorno. In: CONGRESSO NACIONAL DA ASSOCIAÇĀO BRASILEIRA DE EDUCAÇÃO MUSICAL, 20., 2011, Belém. Anais... Belém, 2011.

SALVADOR, E. Um olhar diferenciado na abordagem da educação musical: relato de experiência com uma criança Autista. 2013. Disponível em: <http://musicaeinclusao.files.wordpress.com/2014/01/ relato-de-caso-autismo-e-musica_-ester-salvador.pdf>. Acesso em: 08 maio 2014.

SANINI, C. Autismo e inclusão na educação infantil: um estudo de caso longitudinal sobre a competência social da criança e o papel da educadora. 2011. 174f. Tese (Doutorado em Psicologia do Desenvolvimento) - Instituto de Psicologia, Universidade Federal do Rio Grande do Sul, Porto Alegre, 2011.

SANINI, C.; SIFUENTES, M.; BOSA, C. A. Competência social e autismo: o papel do contexto da brincadeira com Pares. Psicologia: Teoria e Pesquisa, v.29, n.1, p.99-105, 2013.

SANTO, L. A. A. E. O comportamento de crianças com transtorno do espectro artístico no contexto de educação musical - estudo de caso. 2011. Dissertação (Mestrado em Teoria e Pesquisa do Comportamento) - Instituto de Psicologia, Universidade Federal do Pará, Belém, 2011. Disponível em: <http://www.ppgtpc.ufpa.br/documentos/Mestrado/Lady\%20Anny\%20Santos\%20 disserta\%C3\%A7\%C3\%A3o_vers\%C3\%A3o_final_.pdf>. Acesso em: 05 ago. 2013. 
SCHILLING, T. H.; CLIFTON, R. K. Nine-month-old infants learn about a physical event in a single session: Implications for infants' understanding of physical phenomena. Cognitive Development, v.13, n.2, p.165-184, 1998.

SOARES, L. Programa de apoio pedagógico e inclusão: um estudo de caso. Revista da ABEM, v.20, n.27, p. 55-64, 2012.

STONE, W. L. et al. Nonverbal communication in two and three-years-old children with autism. Journal of Autism and Developmental Disorders, v.27, n.6, p.677-696, 1997.

VERBA, M. The beginnings of collaboration in peer interaction. Human Development, v.37, n.3, p.125-139, 1994.

WETHERBY, A. M. Ontogeny of communicative functions in autism. Journal of Autism and Developmental Disorders, v.16, n.3, p.295-316, 1984.

WHALON, K. J.; HANLINE, M. F. The state of inclusion of children with autism spectrum disorder in United Sttes public schools. Revista Educação Especial, Santa Maria, v.26, n.47, p.523-540, 2013. ${ }^{8}$ 
NASCIMENTO, P.S. et al. 